\title{
Tako-tsubo cardiomyopathy following gastroscopy: a complication to consider
}

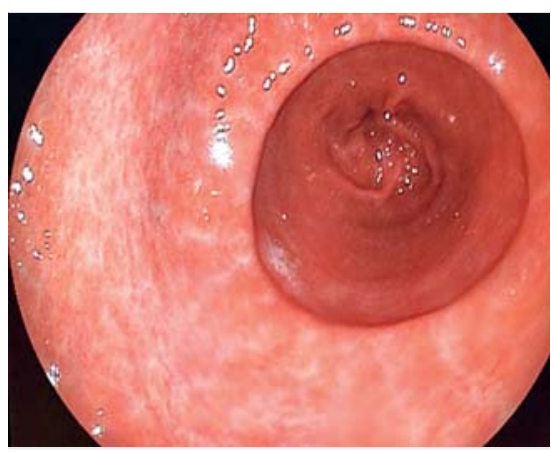

- Fig. 1 Gastrointestinal endoscopy revealed gastric atrophy in the antrum.

A 69-year-old woman, who was a former smoker, presented with dysphagia to solids and liquids and epigastric pain over a period of 8 weeks. An upper gastrointestinal endoscopy was performed, without incident, and revealed gastric atrophy in the antrum ( $\mathbf{F i g}$. 1). Biopsies were taken according to the Sydney protocol.

After the procedure the patient suffered from chest pain. Electrocardiogram revealed $\mathrm{T}$-wave inversion in precordial leads DI-AVL and V2-V5 ( $>$ Fig. 2). Troponin level was also elevated $(0.53 \mathrm{ng} / \mathrm{mL})$. Urgent coronary angiography was per-

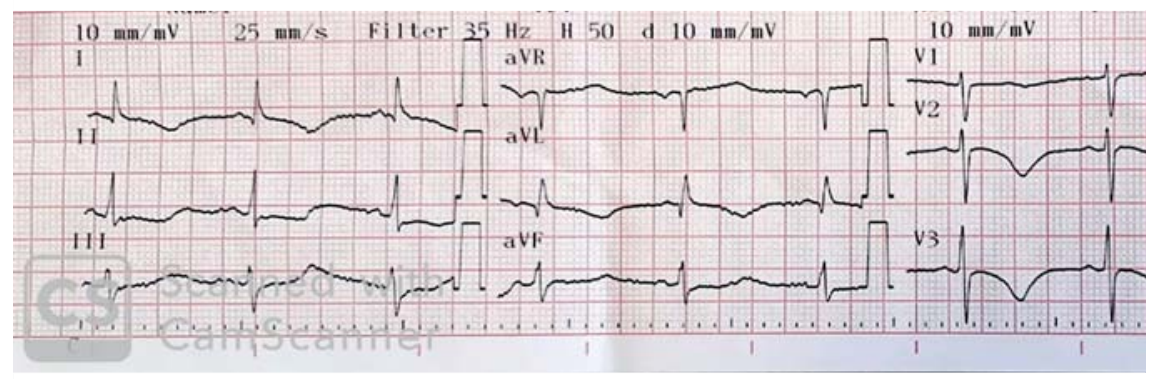

- Fig. 2 Electrocardiogram: T-wave inversion in leads DI-AVL and V2-V5.

formed and revealed entirely normal coronary vasculature. Left ventriculography demonstrated akinesis of the midventricular anterior segment ( $\triangleright$ Fig.3, > Video 1).

Echocardiography showed an ejection fraction of $60 \%$ and confirmed the akinesis of the mid-ventricular anterior segment. The patient's symptoms improved with aspirin and a beta blocker. There were no complications and the patient was discharged after 72 hours, without any symptoms.

A diagnosis of tako-tsubo cardiomyopathy (TTC) following gastroscopy was made based on the transient and completely reversible wall motion abnormal- ities and chest pain syndrome without occlusive coronary disease. TTC is a reversible cardiomyopathy that typically occurs in women over the age of 50 years and can mimic an acute coronary syndrome [1]. There are few reports of TTC after gastrointestinal procedures (oralcontrast radiology and colonoscopy) [2]. It has been suggested that catecholamines may play a role in triggering TTC because patients often have preceding emotional or physical stress [3]. Overall the long-term survival is the same as that of the age-matched population and recurrence is possible [4].

Endoscopy_UCTN_Code_CPL_1AN_2AG
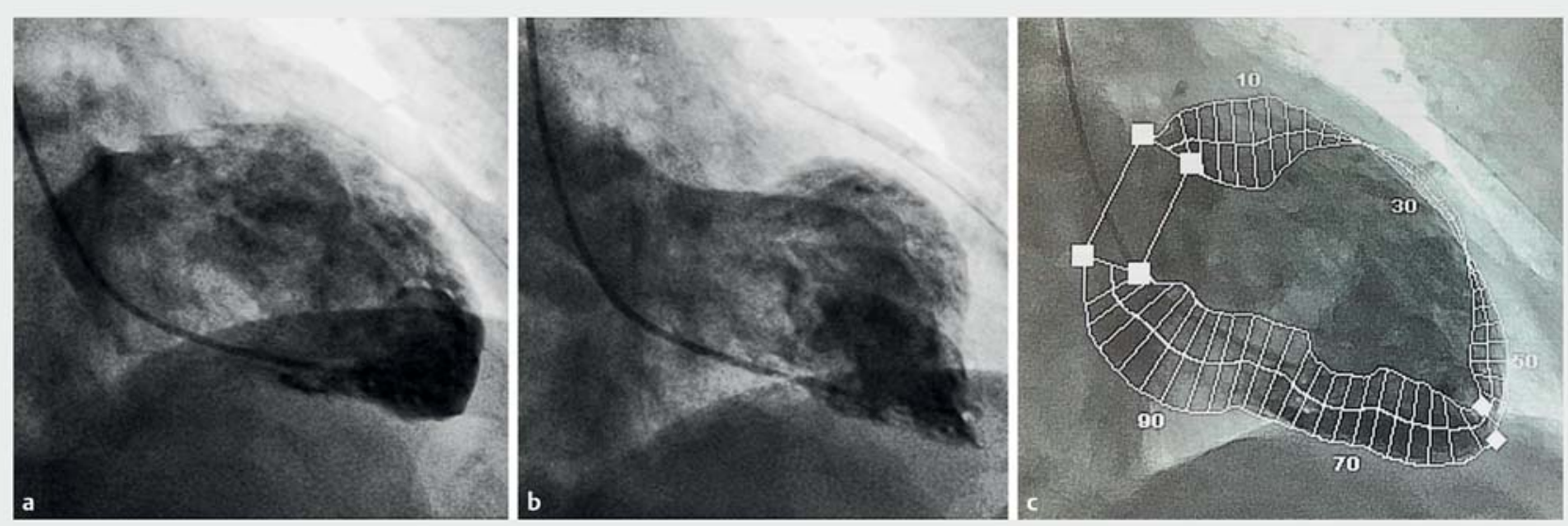

Fig. 3 Ventriculography. a Ventricular diastole. b Ventricular systole. Akinesis in the mid-ventricular anterior segment with contractility preserved in the apical and basal segments of the left ventricle. c Quantitative analysis of the contractility, showing akinesis in the mid-ventricular anterior segment. 


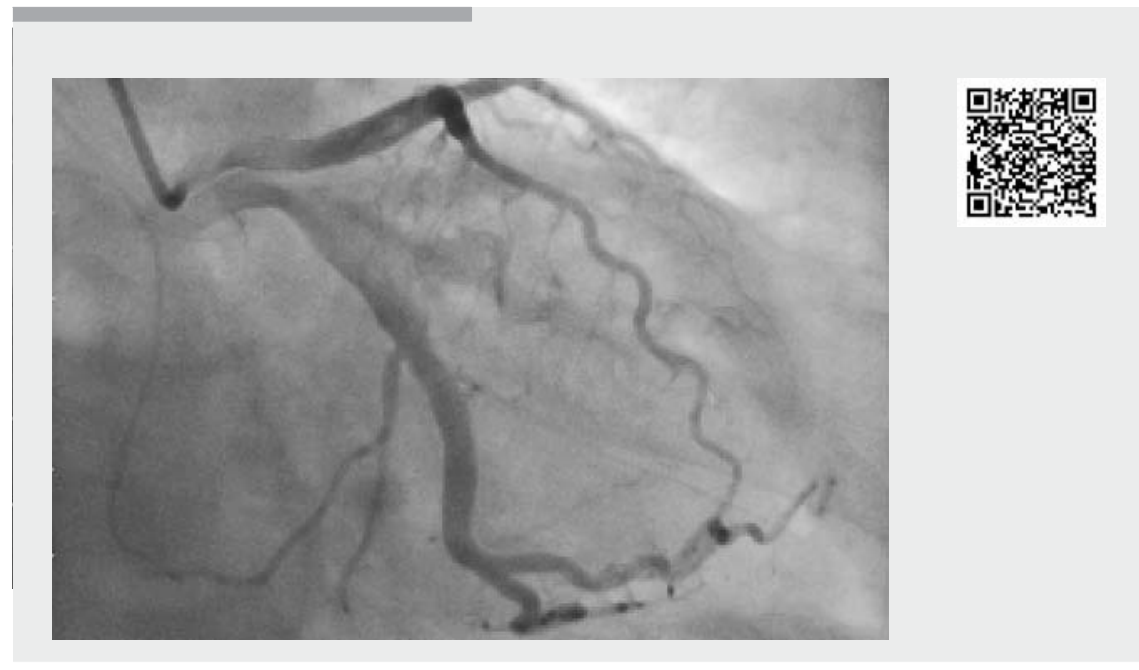

Video 1 Tako-tsubo cardiomyopathy following gastroscopy.

\section{Competing interests}

None

The authors

Martín Oricchio ${ }^{1}$, Rodrigo Dorelo', Juan Pablo Bachini $^{2}$, Daniela Méndez ${ }^{1}$, Adrián Canavesi ${ }^{1}$

1 Clínica de Gastroenterología, Hospital de Clínicas, Montevideo, Uruguay

2 Centro Cardiovascular Universitario, Hospital de Clínicas, Montevideo, Uruguay

\section{Corresponding author}

\section{Martin Oricchio, MD}

Clínica de Gastroenterología, Hospital de Clínicas, Av. Italia S/n CP, 11600,

Montevideo, Uruguay

Fax: +598-2-4872572

martinoricchio@hotmail.com

\section{References}

[1] Patel A, Namn Y, Shah S et al. Takotsubo cardiomyopathy after an upper and lower endoscopy: a case report and review of the literature. J Med Case Rep 2019; 13: 81
[2] Mohammad M, Patel A, Koirala A et al. Takotsubo cardiomyopathy following colonoscopy: insights on pathogenesis. Int J Cardiol 2011; 147: e46-e49

[3] Kurisu S, Kihara Y. Tako-tsubo cardiomyopathy: clinical presentation and underlying mechanism. J Cardiol 2012; 60: 429-437

[4] Kazakauskaité K, Jankauskas A, Lapinskas T et al. Tako tsubo cardiomyopathy: the challenging diagnosis in clinical routine. Medicina (Kaunas) 2014; 50: 1-7

Bibliography

DOI https://doi.org/10.1055/a-1028-6899

Published online: 7.11.2019

Endoscopy 2020; 52: E140-E141

(c) Georg Thieme Verlag KG

Stuttgart · New York

ISSN 0013-726X

\section{ENDOSCOPY E-VIDEOS}

https://eref.thieme.de/e-videos

口回 Endoscopy E-Videos is a free access online section, reporting 回: on interesting cases and new techniques in gastroenterological endoscopy. All papers include a high quality video and all contributions are freely accessible online.

This section has its own submission website at https://mc.manuscriptcentral.com/e-videos 